\title{
Simon Biggs
}

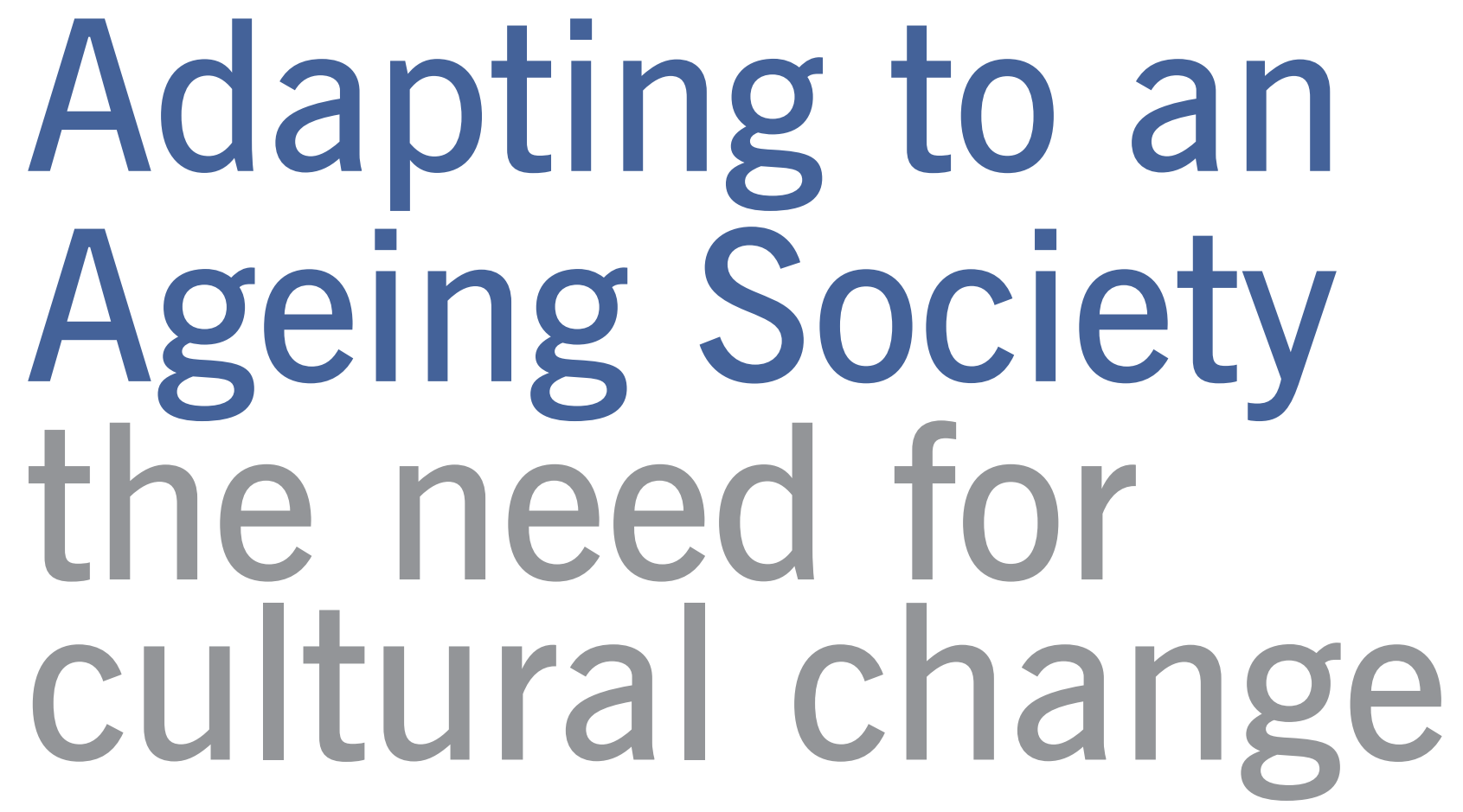

A demographic change, a task of cultural adaptation

In 2050 the global population aged over 60 will reach two billion, making this age group three times larger than it was in 2000. This is a challenge that is facing both mature and emerging economies. The debate on the future shape of a long life is one that is critical to social development in the 21 st century and is increasingly exercising the minds of policy makers throughout the world. The World Economic Forum global risks group has now identified population ageing as one of the five top issues facing the world community in terms of material provision (Beard et al., 2012). If, as the

Simon Biggs is Professor of Gerontology and Social Policy, sponsored by the Brotherhood of St Laurence, in the School of Social and Political Sciences, University of Melbourne, and was a visitor to the Institute for Governance and Policy Studies in February 2014.
World Economic Forum claims, the task of addressing global ageing is principally one of cultural adaptation, the forms that adaptation takes require critical consideration.

Everyone wants to live a long life, no one wants to grow old Much is now well known in terms of overall demographic trends: people are living longer and the numbers of older people relative to younger ones is increasing (Bengtson and Lowenstein, 2003). In other words, with the possible exception 
of some African states and parts of the Russian Federation, we are moving, as a global trend, away from the 'traditional' demographic triangle, with many younger and few older adults, to a column whereby different age groups are becoming more or less equal in size (Bloom, 2011). In many advanced economies the transition has largely been completed, although in emerging ones the speed of this transition is happening at a much faster rate.

In addition, mature-aged individuals are, generally speaking, richer and fitter than preceding generations (Metz and Underwood, 2005), and as a result are developing lifestyles that reflect a mixture of extended youthful activities and novel mature priorities. If one were to try to encapsulate this as a cultural trend it may be to say that 'Everyone wants to live a long life, but no one wants to grow old'.

For societies to respond successfully, to make this transition work, they need to engage in a series of tasks, including a re-design of our cities (World Health Organisation, 2007), the extension of a healthy life (Olshansky et al., 2007), intergenerational negotiation of agerelated roles and expectations (Biggs and Lowenstein, 2011), and a re-evaluation of the contribution of older adults to the societies in which they live (Walker, 2009).

In cultural and in policy terms, the question that arises is what sort of adaptation should we be aiming for? What, in other words, might the relationship between life-course continuity and discontinuity be, and how is it reflected in wider social discourse on the purpose of a long life?

\section{Phase one: more of the same}

In this context, the work of the World Bank (1994) and the OECD (2006), plus the policy statements of numerous nation states (see Commonwealth of Australia, 2010; European Union, 2012) show an emerging international policy consensus. This consensus marks a shift away from a holistic approach to the inclusion of older adults, as reflected in the OECD's report on 'active ageing' (OECD, 1998), to a more restricted approach encapsulated by the title of the seminal document Live longer, Work Longer (OECD, 2006), which

focuses almost entirely on employment as the means of filling the additional years of a long life. This view appears to have become increasingly entrenched following the global financial crisis, such that the European Union's European Year of Active Ageing and Solidarity between Generations programme states: 'Empowering older people to age in good health and to contribute more actively to the labour market and to their communities will help us cope with our demographic challenge in a way that is fair and sustainable for all generations' (European Union, 2012). Whether there are jobs available and ageism can be reduced in the workplace, is another matter. It assumes that a new direction has been found which lies in extending working life and adopting a restricted

\section{... evidence is emerging that many of the assumptions of the 'more of the same' solution to population ageing may not stand up, at least in terms of age as a burden or as a source of resentment from younger age groups.}

understanding of active and productive ageing that has been reduced to work and work-like activities (Moulaert and Biggs, 2013). 'Fair and sustainable' here reflect both the anxiety as well as the promise of 'intergenerational solidarity' around jobs and pensions, that, as Kohli (2005) put it, 'In the twenty-first century, the class conflict seems to be defunct and its place taken over by generational conflict'.

\section{Phase two: exploring difference and} generational complementarity

In contrast to the 'more of the same' approach, a number of writers have emphasised the discontinuous qualities of long-lived experience. The notion of adaptation implies that there is a qualitative as well as a quantitative distinction to be made as the different generations become more equal in demographic size. It has been argued that current policies attempt an erasure of any transition in life priorities, replacing recognition of differing life priorities with a denial of the special qualities that a long life brings with it (Biggs, 2004; Calasanti and King, 2011; Dillaway and Byrnes, 2009; Martinson and Halpern, 2011). There is emerging evidence that while individuals desire continuity of identity, this does not preclude discontinuity of age-related life priorities. A key element of this approach draws not on neoliberal economics but on psychosocial understandings of changing existential tasks that face adults as they grow older (Tornstam, 2005; Dittmann-Kohli and Joop, 2007). A focus on a discontinuity of psychosocial priorities across the adult life course also raises the issue of the degree to which intergenerational agendas overlap, and suggests that a 
solution to the fiscal costs of health - for example, if $60 \%$ of tax revenue is raised outside taxable income (Betts, 2014). A more equitable solution may be to increase a 'longevity dividend', whereby 'the extension of healthy life creates wealth for individuals and the nations in which they live' (Olshansky et al., 2007). This would include adopting policies that extend healthy ageing though investment in prevention and medical innovation, thus creating a longer period of healthy working life. Further, it does not appear that younger adults see their elders as a burden. A number of studies are emerging that indicate that younger adults do not resent caring for older relatives; rather, they want the right work-life balance that allows it. Neither may younger from intergenerational rivalry and towards measures that reinforce a life course-based contract between citizens and the state.

If the first phase of cultural adaptation has been to fill a longer life with the obligation to work, the second may be to discover the complementary skills that different age groups bring to a diverse number of settings and potential contributions to society.

\section{Sticks or carrots in social policy}

A further implication that follows from this is what might be called a stick-versuscarrot approach to workforce policy. If the stick concerns removing benefits (for those relying on statutory pension eligibility) to force older people to look for

\section{Taken together these ... would facilitate the discovery of each age group's contribution to social well-being, and the development of complementary rather than competitive relations between those generations, in the workplace, in the family, in policy and in civil society.}

adults resent paying for others' pensions and health; they just want the same commitment for themselves when their time comes (Gentrans, 2006-2009; Azra and Kohli, 2008; Keck and Blome, 2008; Komp and van Tilberg, 2010). Finally, the longstanding 'lump of labour' fallacy that younger adult unemployment is linked to retaining or recruiting older workers appears to have no empirical evidence to support it. In fact, reduced rates of youth unemployment correlate positively with high levels of mature-age employment, such that: 'An exhaustive search found no evidence to support the theory in the United States. In fact the evidence suggests that greater employment of older persons leads to better outcomes for the young - reduced unemployment, increased employment and a higher wage' (Munnell and $\mathrm{Wu}, 2012$ ). These arguments would tend to re-focus political debate away work which may or may not be there or be appropriate, then the carrot concerns modifying workplaces to make them more age-friendly. A number of studies have shown that this can be achieved by: creating greater choice and flexibility about transitions in and out of work (Taylor, 2006); enhancing the capacity of older workers through training, lifelong learning and anti-discrimination policies (Seiki, Biggs and Sargent, 2012); making workplaces more attractive to both recruit and retain mature-age workers (Manninen, 2011); and adapting policies to facilitate new pathways and meanings associated with work and retirement (Sargent et al., 2013). Perhaps most famously, the car manufacturer BMW successfully adapted their Bavarian production line to make it mature-age friendly and found that productivity increased and absenteeism fell, as did the defect rate (Loch et al.,
2010); in other words, 'It's no longer a project to aid the elderly; it's simply a fresh new plan to improve productivity.'

The question isn't really that we don't know what to do to save money around demographic change, but that the solutions are complex, requiring longterm planning. They are rarely exciting and lack the brouhaha of 'tough' political posturing. The list would include: a shift to focus on prevention in health care rather than reactive intervention; reducing cumulative disadvantage such that social inequalities are addressed early in the life course rather than allowing an accumulation of problems as time progresses; adopting policies that further emphasise community integration rather than residential care; working a few years longer in workplaces designed for age diversity; creating facilitative environments for social engagement through universal/age-friendly design; and business innovation to make agefriendly products at affordable prices.

Phase three: rediscovering whole life course priorities

If the first phase of adaptation has been marked by a 'more of the same' response - filling the vacuum with priorities from elsewhere - and the second a facilitative and intergenerational response to the question of what to do with all those extra years, the third, which is only dimly visible on the horizon, may cause us to address some fundamental questions around the purpose of a long life, the contribution of older adults and a re-shaping of the life course as a whole. The signposts are already there if we wish to follow them.

First would be to embrace the psychosocial discontinuities that occur as we age, rather than fear personal change. The mature half of adult life contains an awareness that we are not, in fact, immortal and have a limited time on this planet. This generates a set of new existential priorities that are only just becoming recognisable. It is not, then, simply that people wish they could spend more time in the workplace.

Second would be a rediscovery of the importance of generational intelligence. This would include the ability both to put oneself in the shoes of another 
generational group and to develop the skills for sustained negotiation between generational interests. As a first step it might include a series of assessments of contemporary frameworks to evaluate the degree to which they facilitate becoming conscious of self as part of a generation, the relative ability to put oneself in the position of other generations, and the relative ability to negotiate between generational positions.

Taken together these two steps would facilitate the discovery of each age group's contribution to social well-being, and the development of complementary rather than competitive relations between those generations, in the workplace, in the family, in policy and in civil society. We have glimpses of these alternative rhythms in the differences between between 'youthful' and 'mature' identities, in agespecific life tasks, changes in perspective, in 'gero-transcendence' and in 'generational intelligence'. They provide a starting point for the question of meaning in later life that is not solely contingent on economic materialism. The 'more of the same' offered by productivist solutions cannot answer these desires; rather, it seeks to suppress them. We should, given this historical turn in age relations, see what it can tell us about the human condition, the ways we lead our lives and the kind of futures we collectively desire.

\section{The journey ahead}

If everybody really does want a long life, it is becoming clearer that few want to grow old as it is currently conceived. The task is of cultural adaptation to a society where the age groups are roughly equal in size and finding new age-specific roles and contributions. Then lasting solutions can be based on intergenerational complementarity. Policy should be less about work continuation versus reinvented retirement, and more about allowing mature adults to develop multiple aspects of their identity, and in so doing permitting the emergence of life course-specific contributions to the wider social good. The role of a progressive social policy would be to make available new social spaces in which these novel forms of age-based identities can emerge. It would rest on a critique not only of physical space, but of temporal relations such as work-life balance across the life course and the meanings attributed to different life phases. Sustainable solutions, those that can stand the test of time and respect the life priorities of different generational groups, can then be negotiated as each party recognises their own and the others' specific contribution. True cultural innovation would lie in the facilitation of new roles adapted to a long life, greater attention to generational interconnection, and discovering new ways of releasing age-specific potential.

\section{References}

Azra, C. and M. Kohli (2008) Pension Reform in Europe: politics, policies and outcomes, 1st edn, New York: Routledge

Beard, J.R., S. Biggs, D.E. Bloom, L. Fried, P. Hogan, A. Kalache and S.J. Olshansky (2012) Global Population Ageing: peril or promise?, Geneva: World Economic Forum

Bengtson, V.L. and A. Lowenstein (2003) Global Aging and Challenges to Families, Life Course and Aging, New York: Aldine de Gruyter

Betts, K. (2014) The Ageing of the Australian Population: triumph or disaster?, report prepared for the Monash Centre for Population and Urban Research, http://artsonline.monash.edu.au/cpur/files/2014/04/ Ageing-of-the-Australian-population-4.pdf

Biggs, S. (2004) 'New ageism: age imperialism, personal experience and ageing policy', in S.O. Daatland and S. Biggs (eds), Ageing and Diversity: multiple pathways and cultural migrations, Bristol: Policy Press

Biggs, S. and A. Lowenstein (2011) Generational Intelligence: a critical approach to age relations, London, New York: Routledge

Bloom, D.E. (2011) '7 billion and counting', Science, 333 (6042), pp.562-9

Calasanti, T. and N. King (2011) 'A feminist lens of the third age: refining the framework', in D. Carr and C. Komp (eds), Gerontology in the Era of the Third Age, New York: Springer, pp.67-85

Commonwealth of Australia (2010) Intergenerational Report: Australia 2050 future challenges, http://archive.treasury.gov.au/igr/igr2010/ report/pdf/IGR_2010.pdf

Dillaway, H.E. and M. Byrnes (2009) 'Reconsidering successful aging: a call for renewed and expanded academic critiques and conceptualizations', Journal of Applied Gerontology, 28 (6), pp.70222
Dittmann-Kohli, F. and D. Joop (2007) 'Self and life-management', in J. Bond (ed.), Ageing in Society, London: Sage

European Union (2012) Europa: European Year of Active Ageing and Solidarity Between Generations, http://europa.eu/ey2012

Gentrans (2006-09), 'Baby Boomers' Generational Transmissions in Finland', the GENTRANS research project, University of Helsinki, data collected by Statistics Finland, available at http://blogs.helsinki.fi/ gentrans/

Irwin, S. (1998) 'Age, generation and inequality', British Journal of Sociology, 49 (2), pp.305-10

Keck, W. and A. Blome (2008) 'Is there a generational cleavage in Europe?', in J. Alber, T. Fahey and C. Saraceno (eds), Handbook of Quality of Life in the Enlarged European Union, 1st edn, London: Routledge

Kohli, M. (2005) 'Generational changes and generational equity', in M.L. Johnson (ed.), The Cambridge Handbook of Age and Ageing, Cambridge: Cambridge University Press

Komp, K. and T. van Tilburg (2010) 'Ageing societies and the welfare state: where the inter-generational contract is not breached', International Journal of Ageing and Later Life, 5 (1), pp.7-11

Loch, C.H., F. Sting, N. Bauer and H. Mauermann (2010) 'How BMW is defusing the demographic time bomb', Harvard Business Review, March

Manninen, O. (2011) Work among the elderly, Kopijyvä (Tampere)

Martinson, M. and J. Haplern (2011) 'Ethical implications of the promotion of elder volunteerism: a critical perspective', Journal of Aging Studies, 25 (4), pp.427-35 
Metz, D. and M. Underwood (2005) Older, Richer, Fitter: identifying the customer needs of Britain's ageing population, London: Age Concern England

Moulaert, T. and S. Biggs (2013) 'International and European policy on work and retirement: reinventing critical perspectives on active ageing and mature subjectivity', in Human Relations, 66 (1), pp.23-44

Munnell, A.H. and A.Y. Wu (2012) Will Delayed Retirement by the Baby Boomers Lead to Higher Unemployment Among Younger Workers?, working paper, Chestnut Hill, MA: Center for Retirement Research, Boston College

OECD (1998) Maintaining Prosperity in an Ageing Society, Paris: OECD OECD (2006) Live Longer, Work Longer, OECD Publishing (online)

OECD (2011) 'Paying for the past, providing for the future:

intergenerational solidarity', background document for ministerial meeting on social policy, Paris, 2-3 May, www.oecd.org/social/ ministerial

Olshansky, S.J., D. Perry, R.A. Miller and R.N. Butler (2007) 'Pursuing the longevity dividend: scientific goals for an aging world', Annals of the New York Academy of Sciences, 1114, pp.11-3
Sargent, L.D., M.D. Lee, B. Martin and J. Zikic (2013) 'Reinventing retirement: new pathways, new arrangements, new meanings', Human Relations, 66, pp.3-21

Seiki, A., S. Biggs and L. Sargent (2012) 'Organizational adaptation and human resource needs for an ageing population', in J.R. Beard et al. (eds), Global Ageing: promise or peril?, Geneva: World Economic Forum

Taylor, P. (2006) 'Work and employment: society', Encyclopaedia of Gerontology, 2nd edn, Oxford: Elsevier

Tornstam, L. (2005) Gerotranscendence: a developmental theory of positive aging, New York: Springer

Walker, A. (2009) 'Commentary: the emergence and application of active aging in Eurpoe', Journal of Aging and Social Policy, 21 (1), pp.75-93

World Bank (1994) Averting the Old-Age Crisis: policies to protect the old and promote growth, New York: Oxford University Press

World Health Organisation (2007) Global Age-friendly Cities: a guide, Geneva: WHO

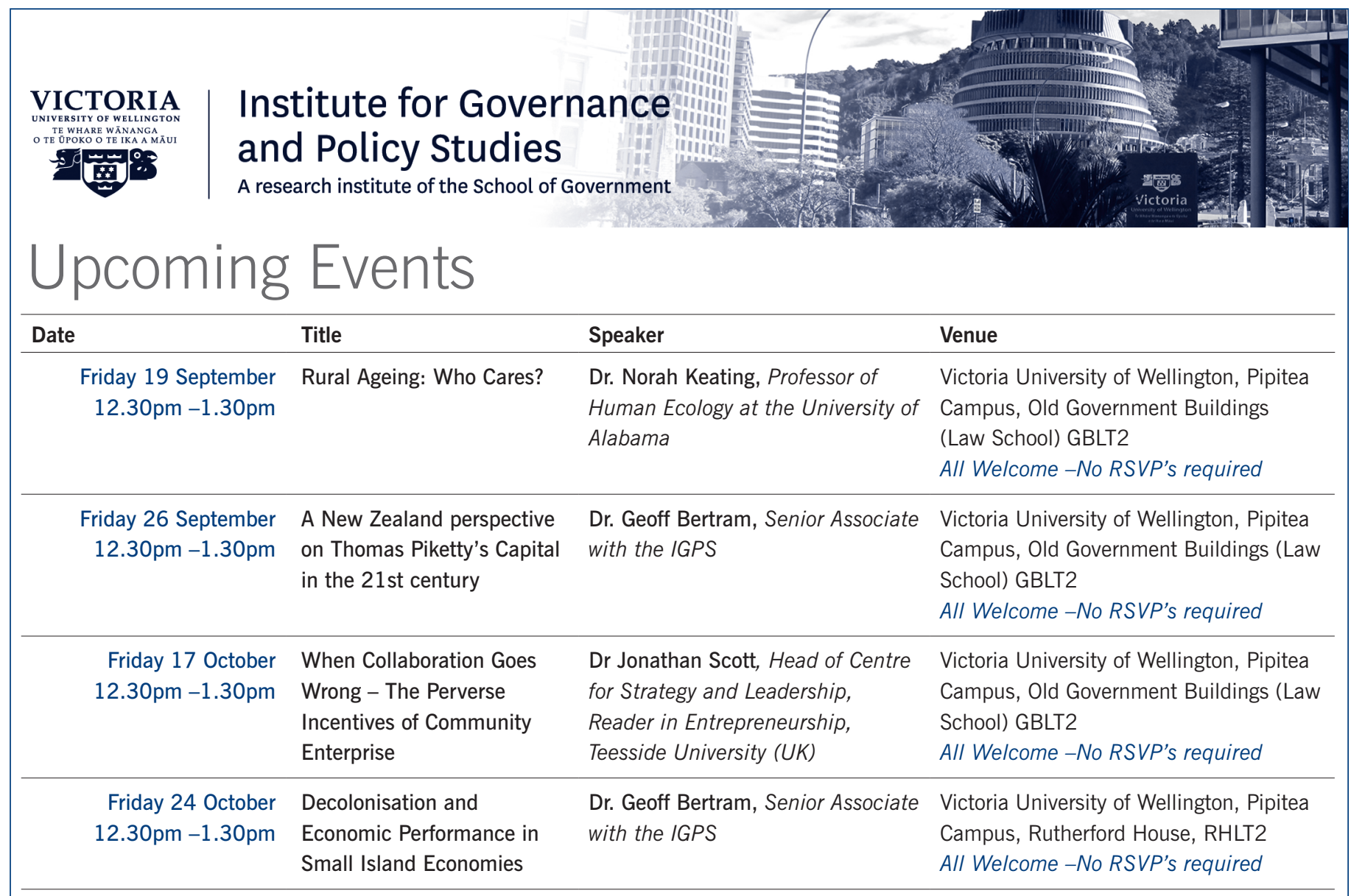

Other speakers confirmed for 2014 include:

Professor John Alford, Professor of Public Sector Management at the Australia and New Zealand School of Government (ANZSOG)

Professor Howard Zehr, Co-director of the new Zehr Institute for Restorative Justice

Professor Alan McConnell, Professor of Public Policy at Sydney University in the Department of Government and International Relations 